International Journal of Biomedicine | June 2019 - Volume 9, Issue Suppl_1: Abstracts From the Second Russian International Conference "Cryo-electron microscopy 2019: achievements and prospects"

POSTER ABSTRACT PRESENTATIONS

SESSION TITLE: COMPLEX AND EMERGING TECHNIQUES IN STRUCTURAL BIOLOGY

DOI: 10.21103/IJBM.9.Suppl_1.P46

\title{
Abstract P-46: Role of Hexamerin in Regulation of Pupa Development in Holometabolous Insects
}

\author{
Mária Gondová ${ }^{1}$, Lucie Valentová ${ }^{1}$, Tibor Füzik $^{1}$, Dominik Hrebík ${ }^{1}$, Antonín Přidal ${ }^{2}$, Pavel Plevka $^{1}$
}

${ }^{1}$ Structural virology, Central European Institute of Technology, Masaryk University, Brno, Czech Republic; ${ }^{2}$ Department of Zoology, Fishery, Hydrobiology, and Apidology, Faculty of Agronomy, Mendel University, Brno, Czech Republic

Background: Hexamerins are the most abundant proteins in the haemolymph of larvae and pupae of honeybee (Apis mellifera) and red flour beetle (Tribolium castaneum). They serve as a source of aminoacids for development in non-feeding pupal stage. Furthermore, they act as juvenile hormonebinding proteins, however, the details of this interaction remain unknown.

Methods: We have isolated hexamerins from honeybee and tribolium pupae and solved their structures by X-ray crystallography and cryoelectron microscopy, respectively.

Results: The structure of honeybee and tribolium hexamerins were resolved to $2.0 \AA$ and $3.2 \AA$ resolution, respectively. They are composed of six identical subunits with sizes around $70 \mathrm{kDa}$ and possess 32 symmetry. The honeybee hexamerin structure revealed that each subunit contains an enclosed hydrophobic cavity occupied by one molecule of putative juvenile hormone. Electron density map of tribolium hexamerin was not of sufficient quality to observe juvenile hormone molecules, however we were able to identify hydrophobic cavity similar to that in honeybee hexamerin.

Conclusion: We hypothesize that proteolytic digestion of hexamerin leads to release of juvenile hormone. Therefore, the consumption of hexamerin is linked to level of free juvenile hormone in haemolymph, affecting the development of pupa. Since both, honeybee and tribolium hexamerins possess similar hydrophobic cavities, possibly occupied by juvenile hormone, we propose this mechanism to be conserved among holometabolous insects.

Key Words: hexamerin • juvenile hormone • honeybee tribolium

International Journal of Biomedicine. 2019;9 Suppl 1: S37-38. doi: 10.21103/IJBM.9.Suppl_1.P46

(C)2019 International Medical Research and Development Corporation 